Binghamton University

The Open Repository @ Binghamton (The ORB)

$5-2007$

\title{
Putting the Pieces Together: A Comprehensive Framework for Understanding the Decision to Contract Out and Contractor Performance
}

\author{
Anna A. Amirkhanyan \\ American University, amirkhan@american.edu \\ Hyun Joon Kim \\ Korea University - Korea, joonk@korea.ac.kr \\ Kristina T. Lambright \\ Binghamton University--SUNY, klambrig@binghamton.edu
}

Follow this and additional works at: https://orb.binghamton.edu/public_admin_fac

Part of the Public Administration Commons

\section{Recommended Citation}

Amirkhanyan, Anna A.; Kim, Hyun Joon; and Lambright, Kristina T., "Putting the Pieces Together: A Comprehensive Framework for Understanding the Decision to Contract Out and Contractor Performance" (2007). Public Administration Faculty Scholarship. 24.

https://orb.binghamton.edu/public_admin_fac/24

This Article is brought to you for free and open access by the Public Administration at The Open Repository @ Binghamton (The ORB). It has been accepted for inclusion in Public Administration Faculty Scholarship by an authorized administrator of The Open Repository @ Binghamton (The ORB). For more information, please contact ORB@binghamton.edu. 
This is the accepted version of a paper published in International Journal of Public Administration, This paper has been peer-reviewed but does not include the final publisher proof-corrections or journal pagination

\section{Putting the Pieces Together: A Comprehensive Framework for Understanding the Decision to Contract Out and Contractor Performance}

Anna A. Amirkhanyan, School of Public Affairs, American University, Washington, DC, USA Hyun Joon Kim, Department of Political Science, Texas Tech University, Lubbock, Texas, USA

Kristina T. Lambright, Department of Public Administration, Maxwell School of Citizenship and Public, Affairs, Syracuse University, Syracuse, New York, USA

Contracting out is currently one of the most prevalent mechanisms of the privatization movement. Understanding its trends and rigorously analyzing its implications is an increasingly salient issue for public management research. This article builds a multi-stage theoretical framework addressing two broad research questions. The first is to identify the array of economic, political, organizational, and institutional factors that may impact a government agency's decision to contract out. The second is to detail the various organizational and environmental factors influencing contractor performance. Particular attention is paid to effective contract monitoring and its relationship to contractor performance.

We are grateful to Stuart Bretschneider, Particia Ingraham, and Brinton Milward for useful comments on an earlier draft.

Address correspondence to Hyun Joon Kim, Department of Political Science,

Texas Tech University, Box 41015, Lubbock, TX 79409-1015, USA; E-mail: joon.kim@ttu.edu

\section{INTRODUCTION}

In response to the government's increasing reliance on private markets to deliver taxpayer-funded services, a new stream of public administration liter-ature focusing on governance has been developed. According to Milward and Provan[1], the study of governance examines coordination and collaboration within networks of government agencies and private organizations. Designing and managing these networks is becoming one of the central tasks for "the new world of devolved public policy."[1] New governance studies explore a wide range of mechanisms which go beyond the traditional emphasis on authority and sanctions. In particular, alternative forms of service delivery have become a major focus of research.

Contracting out is currently one of the most prevalent service delivery mechanisms that involve private parties. Kelman[2] defines contracting out as "a business arrangement between a government agency and a private entity in which the private entity promises, in exchange for money, to deliver certain products or services to the government agency or to others on the government's behalf." The phenomenon of contracting out is not new. However, its prevalence has grown significantly over the last several decades. Understanding these trends and their implications is an increasingly salient issue for public administration.

This article builds a theoretical framework addressing two broad research questions. First, "What factors may impact a government agency's decision to contract out a particular 
service?" Second, "What factors influence contractor performance?" To address the first issue we identify the array of economic, political, organizational, and institutional factors that may affect the decision to contract out. Secondly, we detail the various organizational and environmental factors that could potentially influence contractor performance.

The vast majority of the literature on contracting out contains normative propositions on why government agencies should contract out. However, very little research rigorously analyzes the factors that actually influence a government agency's decision to contract out. The first objective of this study is to go beyond the prescriptive approach to the contracting-out decision and develop a model that incorporates not only market-based, but also political, institutional, and organizational considerations.

Most studies on contract performance focus exclusively on comparing the costeffectiveness across various institutional arrangements. This article stresses the need to analyze a variety of possible outcomes beyond the traditional economic indicators. To address this limitation in the existing contracting-out literature, we propose an alternative framework that empha-sizes the quality of contractor performance. Specifically, the second objective of this study is to examine different factors that affect contractor performance. Particular attention is paid to effective contract monitoring and its relationship to contractor performance.

\section{Framework for Contract Decision and Performance}




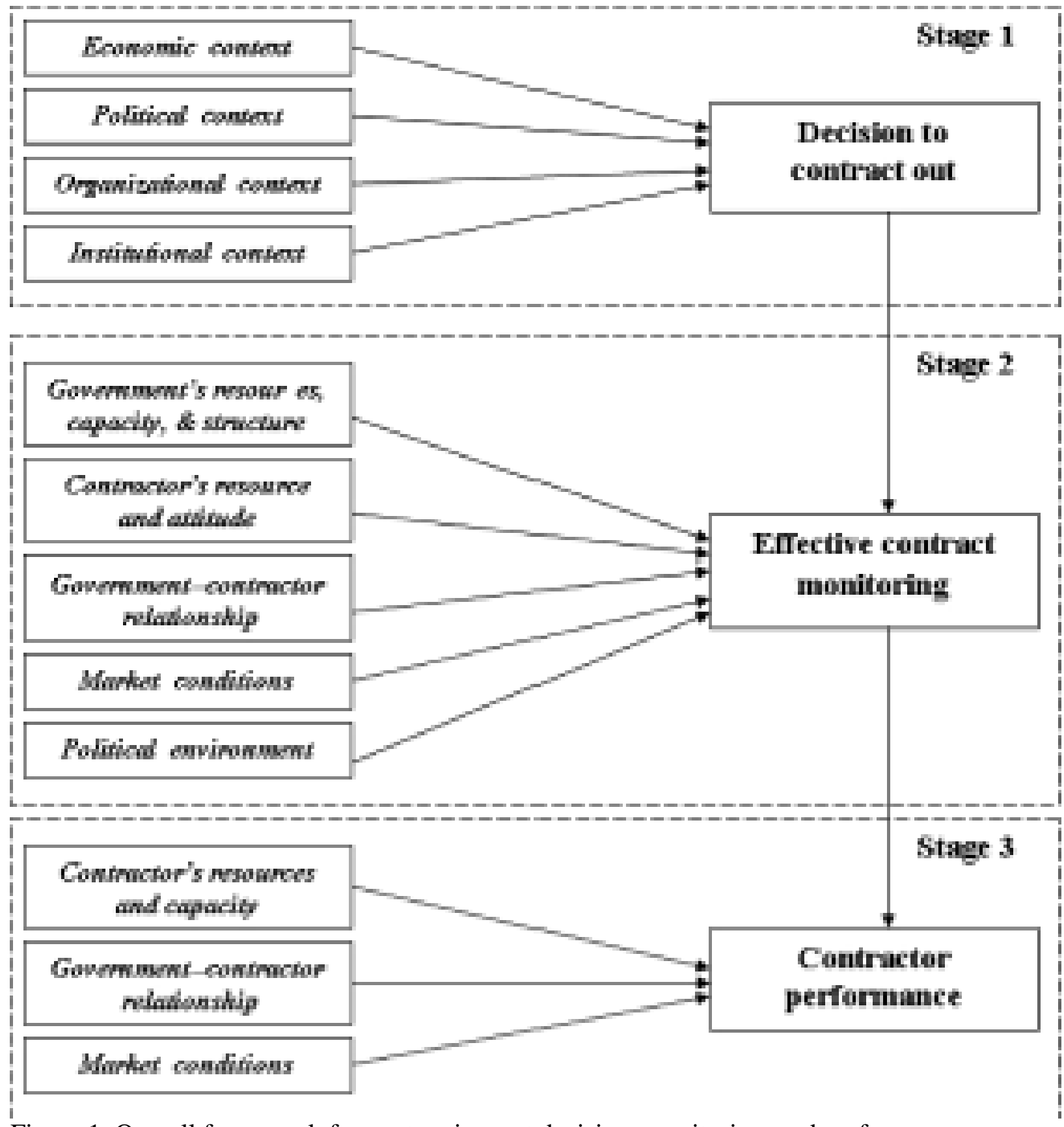

Figure 1. Overall framework for contracting-out decision, monitoring, and performance.

Our analysis is based on a literature review. Contracting out has been written about extensively in a number of disciplines including public admin-istration, law, business, and economics. We focused mainly on the body of public administration literature although we also briefly discuss agency and transaction cost theories in developing our framework. Our review primarily concentrated on literature that developed some theoretical framework for understanding the contracting-out decision and/or contractor performance. In addition, this article incorporates some empirical findings on contracting out that facilitate theory building. The proposed framework is not limited to the constructive synthesis of existing theories on 
contracting out. It also reflects our own understanding and analysis of some of the important factors related to the two research questions.

The body of this article consists of three major sections. The first section analyzes the factors affecting the decision to contract out. The second and third sections are causally linked to each other: The second section discusses the determinants of effective contract monitoring, while the third section analyzes how effective monitoring, along with other factors, influence contractor performance. We do not examine the interdependence of different factors identified in our theoretical model in an exhaustive way. Our framework is only intended to serve as a broad foundation upon which future, more fully specified models focusing on narrower research questions can be based.

\section{STAGE ONE: CONTRACTING DECISION}

As discussed in the introduction, contracting out has become an increas-ingly common method of public service delivery. However, the extent to which different government agencies contract out services varies considerably. Moreover, even within the same governmental agency, some services are directly provided by public employees while other services are contracted out. The first stage of our framework is depicted in Figure 2 and identifies several factors theorized to influence a government agency's decision to contract out a service. These factors are grouped into the four following contexts: economic, political, organizational, and institutional. As Hirsch[3] notes, most studies examining the contracting-out decision-making process focus exclu-sively on a single factor while ignoring other important causes. Our model

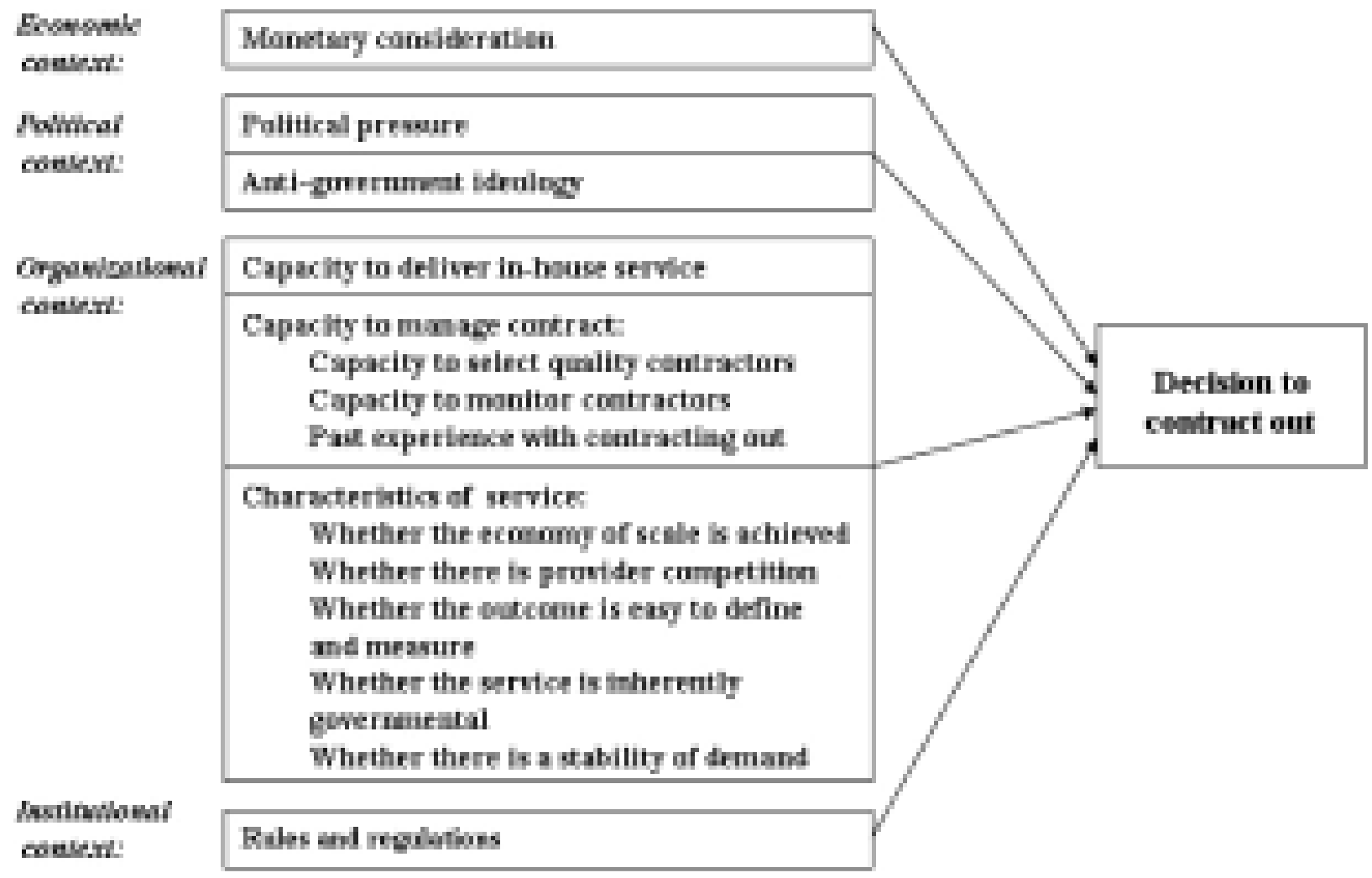

Figure 2. Stage 1: Decision to contract out. 
attempts to fill this gap in the literature by developing a more comprehensive framework for studying this question.

Numerous studies on the contracting out decision cite monetary consid-erations as a key factor.[4-9] The monopoly that the government commonly has on the services it produces does not encourage efficiency. According to economic theory, it is likely to cost a government agency less to contract out a service than to produce it in-house because of provider competition. In situations where services are contracted out, government agencies typically select contractors based on some type of competitive bidding process. As a result, service providers will have an incentive to produce the lowest-cost, best-quality services they can in order to obtain and keep government contracts. In a situation where a government agency is being pressured to reduce service delivery costs, especially in cases when economic delivery is more important than control and accountability,[10] policymakers may be more likely to contract out services than in situations that are not subject to as much pressure to reduce costs.

In addition to monetary considerations, political factors are likely to influence a government agency's decision to contract out a service. One such factor is the presence of political pressure on government agencies from outside groups. These outside groups may either support or oppose the contracting out of a particular service and have the potential to impact the decision-making process in both public and private forums.[11] In situa-tions where outside groups support contracting out, one would expect the probability of a government agency adopting this policy to increase. One example of an outside group that is likely to pressure government agencies to contract out is potential contractors. Government contracts offer this group a mechanism for expanding beyond their traditional markets.[12] Politicians also may pressure government agencies to contract out because they would like to use this policy to reward important constituents with lucrative government contracts.[9] On the other hand, pressure from public employee unions is likely to decrease the odds that this policy is adopted.[5] Unions frequently oppose contracting out because they fear it will result in lower wages for their members and will diminish the union's influence.

Another political factor that is likely to influence a government agency's decision to contract out a service is the dominance of anti-government political ideology. In this article, political ideology is defined as a shared set of beliefs regarding the appropriate size and role of government. Anti-government political ideology refers to the political belief that "government should not engage in the provision of any services that organizations in the private sector can and will provide"'[13] As the prevalence of this ideology increases within a jurisdiction, the likelihood that a government agency will contract out increases as well. Contracting out allows government agencies to provide new services without acquiring new physical assets or hiring additional government workers other than those required to monitor new initiatives.[14,15] In addition, by contracting out services that are already provided by the government, an agency may be able to reduce its size.

Organizational factors may also be considered in the contracting-out decision. For example, a government agency's capacity to deliver the service in-house is important. In this context, capacity refers to both the human resources and physical facilities needed to provide the service. If a government agency evaluates itself as lacking adequate capacity, it may be more likely to consider contracting with private providers who have expertise in the given service. Both DeHoog[16] and Morgan[17] present empirical evidence supporting this argument. On the other hand, function should not be outsourced in cases when significant capital investments in equipment or facilities have already been made in the public sector.[10] 
When deciding whether to contract out a particular service, government agencies are likely to consider not only their capacity to provide the service but also their capacity to manage the entire contracting out process. Our framework includes several dimensions of a government's capacity to manage contracts.[18] One consideration is whether the government agency believes it has the capacity to analyze information about various contract bidders. In a situation where a government agency lacks this capacity, one would expect that the probability that the government agency would select an incom-petent contractor would increase. Another important aspect of the capacity to manage contracts is related to monitoring contracts once the contractors are selected.[15,19] Contracting and procurement literature has voiced concerns about the loss of specialized expertise after privatization,[20] which in turn can lead to a decline in contract monitoring capacity. If a government agency lacks the capacity to monitor, it will be difficult for the government agency to hold contractors accountable for the services they provide.

From the transaction cost economics perspective, contracting out as an economic transaction is associated with the costs of searching, gathering, and evaluating market information and the costs of creating and enforcing contractual agreements.[21] When a government agency lacks the capacity to manage contracts and monitor contractors, the transaction costs it incurs to build its capacity may actually exceed the economic benefits expected from contracting out. Therefore, if a government agency cannot afford the transaction costs involved with developing organizational capacity to manage the entire process of contracting out, it may opt for in-house provision of the service.[22] For these reasons, a government agency that lacks either selection or monitoring capacity is expected to be less likely to contract out services.

In addition to the current capacity to select and monitor contractors, past experience with contracting out is the final dimension of capacity incor-porated into our framework. Monitoring contracts involves a very different set of skills than direct service provision.[6] Past experience is expected to indirectly impact the contracting-out decision. A government agency with contracting-out experience enters a new contracting relationship with first-hand knowledge about past successful and/or unsuccessful contracting-out strategies. Moreover, these experiences have given the government agency opportunities to build capacity in selecting and monitoring contractors. One would expect that a government agency that has had positive experiences with contracting out would be more confident in its ability to select and monitor contracts and therefore be more likely to contract out. The reverse is likely to be true in cases where the government agency has had negative experiences with contracting out.

Characteristics of a service are also likely to play a role in the contracting out decision. Based on the contracting out literature, character-istics a government agency may consider include:

1. can economies of scale be achieved;

2. is there provider competition;

3. is the outcome of a service easy to define and measure;

4. is it an inherently governmental service; and

5. is there stability of demand.

Some services require large infrastructure investments. If a contractor has the necessary service provision infrastructure, but a government agency lacks it, the government agency may decide to contract out that service in order to take advantage of economies of scale.[2,23] Due to different jurisdictional limits, it is likely to be easier in some cases for private-service providers 
to achieve economies of scale. Unlike government agencies, private-service providers are not limited to providing services within a certain political juris-diction. In a case where economies of scale can be achieved by providing services across different political jurisdictions, it will cost the government agency in one of these jurisdictions less to contract out than to produce the service in-house. Under these conditions, one would expect the probability that the government agency would contract out to increase.[3]

As previously discussed, the assertion that contracting out is likely to cost less than producing in-house assumes there is provider competition. Using Van Slyke's definition, provider competition exists when "a market contain[s] a range of provider alternatives from which government can decide who is best positioned to deliver the contract services with the highest quality, lowest cost, and greatest expertise."'24] According to Domberger and Rimmer,[25] provider competition exists when:

1. the government agency can identify more than one potential contractor that can provide high-quality services efficiently, and

2. a competitive bidding process is used to select contractors.

In order for a contractor to have an incentive to produce the lowest-cost, best-quality services it can, both of these conditions must be satisfied.[3,26] Therefore, in the event that at least one of these conditions is not met, one might expect that a government agency would be less likely to contract out.[18]

Another characteristic of a service to be considered is whether it is easy to define and measure the outcomes. When a service has intan-gible outcomes, developing performance measures for the service is often more complicated.[27] Moreover, controversial performance measurement can compromise a government agency's ability to hold contractors accountable for the services they provide. Consequently, government agencies may be more reluctant to contract out the services with less tangible outcomes than the services with easily measurable ones.[18]

Another important consideration is the degree to which a particular service is considered to be inherently governmental or "core." Drawing on Guttman,[28] inherently governmental functions in this article refer to services that have security or accountability concerns which make it important for government to directly oversee their delivery. Following Wilmot,[10] inher-ently governmental services in our model also imply functions of high strategic importance and those dealing with confidential information. The literature on public procurement points out that certain decision-making models involve a critical step of classifying activities as core or non-core before applying cost analysis to non-core services. Core activities are those that must be performed to fulfill an organization's primary mission.[10] If a service which is considered to be inherently governmental or core is not adequately provided, the existence of the government agency responsible for this policy area could be jeopardized. Under these circumstances, one would expect the government agency to be more likely to provide the critical services in-house rather than contracting out for these services, where monitoring is more complicated. Social, political, and demographic changes can alter whether a particular function is considered to be inherently governmental. One recent example is airport security, which had not been considered inherently governmental before $9 / 11$, but since then it has been nationalized.

Stability of demand refers to the extent to which the need for a particular service fluctuates. Because hiring contractors as needed is easier than hiring and firing public employees, who are protected by the civil service system, one would expect that a government agency would be more likely to contract out in cases where demand for a service is unstable.[2] 
Contracting out provides the flexibility that is needed for temporary projects without requiring substantial, on-going financial investments.

Finally, the institutional context of an organization is theorized to impact a government's decision to contract out. In our framework, institutional factors refer to the rules and regulations of various government bodies that affect the environment in which a government agency operates. Institutional settings impose certain structures and procedures on government agencies.[30] As Peters[30] argues, a government agency's institutional setting often shapes the policy decisions that it makes. For example, civil service rules may make it more difficult for a government agency to contract out services.[3,10] In addition, DeHoog[16] provides empirical evidence that funding regulations can impact a government's decision to contract out services.

\section{STAGE 2: EFFECTIVE CONTRACT MONITORING}

The first stage of our framework focused on the factors affecting the decision to contract out. Once that decision has been made, it is also important to consider the various factors that impact how effectively a government agency monitors a contractor. Developing a theoretical framework that attempts to answer this question is the primary purpose of this section of our article. Effective contract monitoring is what Kettl[6] refers to as the "smart buyer" challenge for government when contracting out services. In order to be a smart buyer, a government agency must know:

1. what service it wants to buy,

2. who it wants to buy the service from, and

3. the quality of what it has purchased.

Agency theorists have highlighted effective contract monitoring as a critical factor affecting contractor performance.[1,31] With the dramatic increase in the contracting out of public services, understanding the factors impacting government's effective monitoring of contracts is an issue that is clearly relevant to public administration scholars and practitioners. Yet, surprisingly little theoretical or empirical research examines this topic. One notable exception is Romzek and Johnston.[32] Brown and Potoski[33] also examine the issue of contract monitoring but focus on government's invest-ments in this task rather than government's efficacy at performing it.

In the context of this article, the factor we are trying to explain in Stage 2, effective contract monitoring, refers to:

1. whether the government agency collects information from contractors in a timely manner that accurately captures the quality and quantity of services being delivered, and 2. whether the government agency uses the information it collects to evaluate contractor performance and to make programming and policy decisions.

In Romzek and Johnston,[32] their dependent variable, contract implement tation and management effectiveness, refers to the design, implementation, and evaluation stages of the contracting process. In contrast, in our framework effective contract monitoring only involves the implementation and evalu-ation stages and does not include the design stage. Aspects of the design stage 


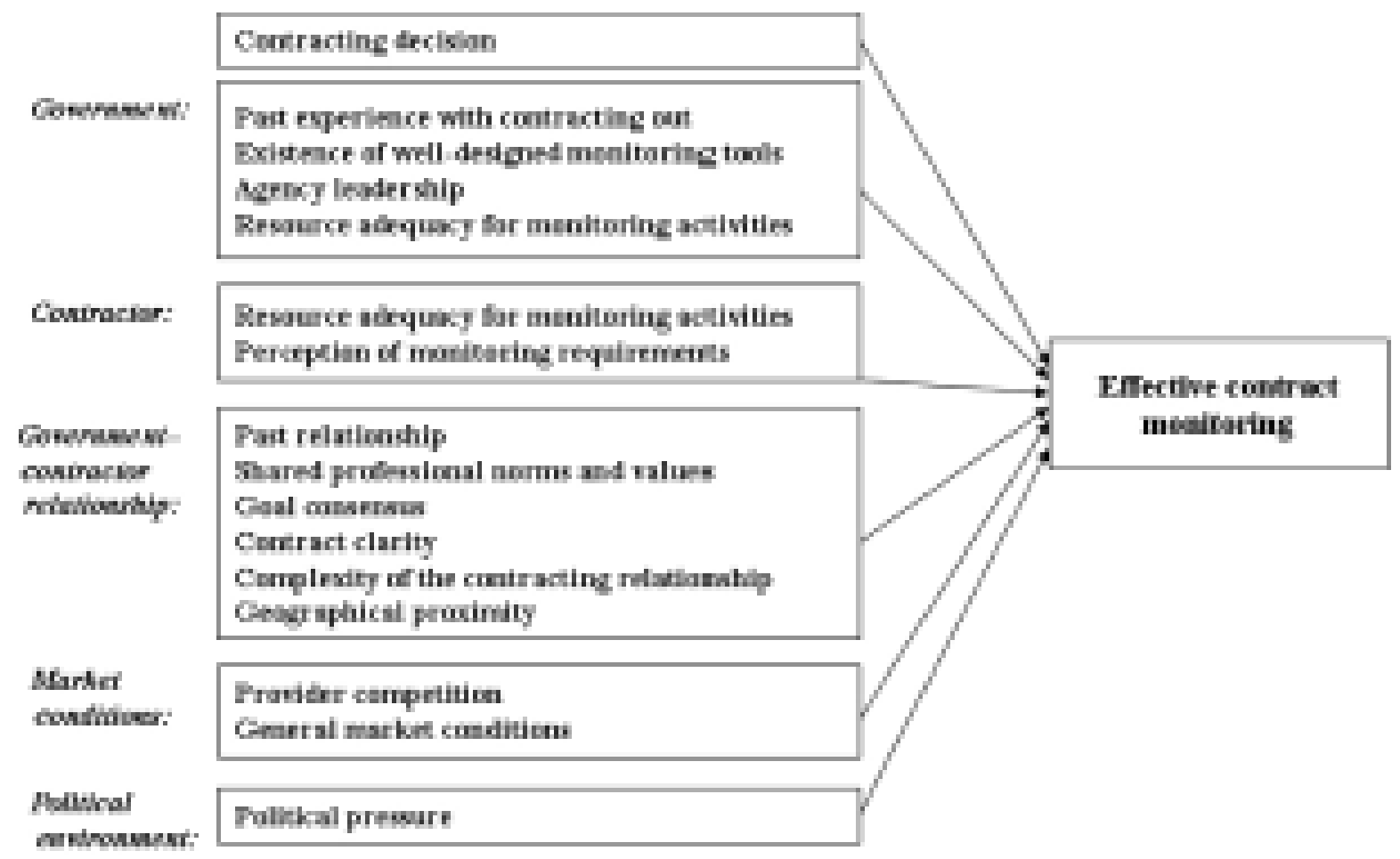

Figure 3. Stage 2: Effective contracting monitoring.

such as the existence of well-designed monitoring tools and contract clarity are theorized to be causally linked to contract implementation and evaluation.

Stage 2 is directly linked to Stage 1 in our framework. Specifically, we theorize that the contracting decision itself is likely to impact the monitoring process and hence the extent to which monitoring is effective. For example, if the decision to contract out was a political favor, one would expect this to have important implications for the monitoring process. In this situation, politicians may pressure bureaucrats not to scrutinize the quality of services that the contractor is providing and thus compromise bureaucrats' ability to effectively monitor the contract.

In addition to the contracting decision, several other factors are likely to impact its effectiveness in monitoring contracts. One broad set of factors included in Stage 2 of our framework relates to the government agency:

1. past experience with contracting out,

2. the existence of well-designed monitoring tools,

3. agency leadership, and

4. resource adequacy.

As discussed in the first stage of our framework, past experience with contracting out gives the government agency opportunities to build capacity in monitoring contractors. As a result, a government agency with past contracting-out experience would be expected to be more effective at monitoring contracts than a government agency with no past contracting-out experience. 
A number of studies identify the existence of well-designed monitoring tools as impacting effective monitoring.[26,27,32] A government agency using well-designed monitoring tools would be more likely to collect data that accurately captures the quality and quantity of services being delivered than an agency using poorly-designed tools. Drawing on work by Kane and Lawler,[35] a well-designed measure:

1. has construct validity,

2. is reliable,

3. has the ability to discriminate between different performance dimensions,

4. $\quad$ is free from bias, and

5. captures the totality of performance and not extraneous issues.

The existence of well-designed monitoring tools is likely to be related to the type of service that is being contracted. As previously detailed, developing monitoring tools is often more complicated for services that have outcomes which are difficult to define and measure than it is for services that have outcomes which are easy to define and measure. Thus, the overall monitoring process is more difficult for the services with outcomes that are more compli-cated to define.

Agency leadership has been shown to positively affect the performance of government agencies.[36] One would expect this same relationship to be true in the case of contracting out. In situations where senior management places a high priority on subordinate staff conducting contract monitoring activities and provides necessary guidance, we hypothesize that contract management would be more effective.

One factor can be important in the context of both the contractor and government agencies. Resource adequacy, when used in relation to government agencies, refers to the availability of stable and sufficient resources for monitoring activities. Similarly, a contractor with adequate resources will have stable and sufficient resources available to comply with the government agency's reporting requirements. The existence of adequate resources has been included in several theoretical models on successful policy implementation.[34,37] Moreover, Romzek and Johnston[32] present empirical evidence indicating that resource adequacy is an important factor influencing effective contract monitoring. Both the government agency and contractor need to have enough financial resources to be able to hire staff qualified to perform the required monitoring tasks and to ensure that staffing levels are adequate. Thus, the probability that the monitoring will be effective is likely to be higher in a case where resources are adequate than in a case where this condition is not satisfied.

The other factor included in Stage 2 of our framework that relates to the contractor is contractor perception of monitoring requirements. We theorize that there are two different dimensions of contractor perception. Building on empirical findings by Bernstein,[38] one dimension refers to the extent to which a contractor believes that the data collected for monitoring purposes accurately and fully captures the quality and quantity of the services delivered. With respect to this dimension, contractors can be classified by whether they believe the data collected is a valid and reliable measure of service quality and quantity. Another important dimension of contractor perception relates to how the contractor believes that the government agency will use the information it collects when making evaluations regarding contractor performance. Applying the work of Jackson and Dutton,[39] performance evaluations can be viewed in one of four ways: 
1. threat-consistent,

2. opportunity-consistent,

3. ambiguous (consistent with both opportunities and threats), or

4. neutral (neither consistent with opportunities or threats).

In terms of this dimension, contractors can range from those that view the monitoring requirements purely with suspicion and as threatening to those who view the monitoring process as purely an opportunity for constructive feedback. These perceptions are likely to affect how a contractor interacts with the government agency and may facilitate or hinder the contract monitoring process.

The discussion in this section up to this point has focused on factors that relate to one organization: either the government agency or the contractor. In addition, several factors describing the relationship between the government agency and contractor are likely to impact the effective monitoring of contracts. Both Bennett and Ferlie[40] and Smith[41] discuss how informal, relational sanctions can be used to regulate contracts in instances where contracting involves complex, long-term exchanges. Key characteristics that can be used to describe a past relationship between a government agency and contractor include the length and quality of the relationship. In a situation where a government agency and contractor have a long-standing relationship built on mutual trust, the contractor may be compelled to satisfy contract requirements more out of a sense of duty rather than as adherence to the formal contract or legal sanctions.[40] Thus, it is likely to be easier for a government agency to monitor this type of relationship than a relationship that is more contentious or where mutual trust has not yet developed.

The contracting-out literature identifies shared professional norms and values between the government agency and contractor as another factor that shapes the contracting process.[26,34,40] In cases where the staff from the government agency and contractor has received similar professional training, it is more likely that the two entities will agree on how services should be delivered and monitored. Furthermore, literature argues that cooperative norms, or shared beliefs that two parties have to work together in order to be successful in a relationship, are key dimensions of the government-business relationship.[10] In cases where there is a high degree of agreement on various critical issues, monitoring would be expected to be easier for the government agency.

Goal consensus is closely related to the existence of shared professional norms and values. There are two important components of goal consensus identified in the general literature on policy implementation: goal clarity and goal agreement.[34,37,44-46] A necessary, but not sufficient, condition for goal consensus is that the goal of the contracting relationship must be clear to both the government agency and contractor. Matland[44] asserts that ambiguous policies hamper monitoring the policy implementation process and the establishment of accountability mechanisms. Assuming that the goal of the contracting relationship is clear, there must also be agreement between the government agency and contractor that the goal is appropriate for goal consensus to exist. Shared professional norms and values are likely to enhance the probability that a government agency and contractor will agree on contract goals.

Goal consensus is expected to increase the odds that a government agency's monitoring will be effective for two reasons. In situations where there is goal consensus, the likelihood of communication problems between the government agency and contractor is reduced. It is also 
likely to be easier to create monitoring tools that both the government agency and contractor believe accurately capture the quality and quantity of services being delivered.

In addition to being a key component of goal consensus, clarity is likely to matter in terms of what a contract specifically says. Agency theory focuses on the agency relationship in which one party (the principal) delegates a task to another party (the agent). According to agency theory, problems can arise with this arrangement when the goals of the principal and agent conflict and when it is difficult or costly for the principal to monitor the activities of the agent.[47] Under these conditions, there is an informational asymmetry between the principal and agent, and the government agency's ability to monitor the contractor is hampered.[21,48] However, contract clarity can reduce the impact of this informational asymmetry on the contracting relationship. Monitoring contracts in which the service delivery mechanisms and outcome measures are clearly stated is likely to be straightforward because it will be easy to tell if contractors are "shirking" their responsibilities.

The complexity of the organizational structure for delivering services should also be considered. In many cases, a government agency is contracting out a whole service system, and the contractor must set up a network that jointly delivers services to clients with multiple problems.[1] The complexity of the organizational structure for delivering services will impact how easily information regarding contractor performance can be transmitted to the government agency. This may result in variations in the government's contract monitoring effectiveness, as one would expect that monitoring a joint production function would be much more difficult than monitoring the work of a single organization. As Romzek and Johnston's work[32] highlights, one aspect of the organizational structure for delivering services that is particu-larly relevant when considering complexity is the number of subcontractors involved in the contracting relationship. Subcontractors are directly respon-sible to the contractor, not the government. As a result, it is likely to be more difficult for the government to assess whether the information collected from a subcontractor accurately captures the quality and quantity of services they are providing. Moreover, the only leverage that a government has to sanction a subcontractor is indirectly through the contractor.

A final characteristic of the relationship between a government agency and contractor included in our framework is the geographical proximity between the two entities. In cases where there is a significant distance separating the two, it will be logistically more challenging for the government to monitor the contractor's activities. There will be less opportunity for faceto-face communication. This may increase the likelihood of misunder-standings. In addition, certain monitoring techniques such as unannounced site visits are not very feasible.

Market conditions of the service are also likely to influence how effective a government agency is at monitoring a contractor. According to Romzek and Johnston, [32] greater provider competition will enhance a government agency's ability to monitor a contractor. Under conditions of greater provider competition, Romzek and Johnston argue that a contractor will be more likely to comply with reporting procedures because it will be more fearful of losing its contract if it does not comply. General market conditions of a service are another consideration. If there is an overall decline in revenues for an entire service sector, agencies in this sector are likely to have incentive to reorganize the distribution of their expenses in such a way that the cuts they have to make are minimized. An obvious way for agencies to do this is to shift as many of their expenses as possible so that they will be covered by remaining funding sources. As a result, agencies in this sector may try to receive government reimbursement for activities that were not intended to be covered by government contracts. As a result of these incentives, 
knowledge of declining revenues for an entire sector may prompt a government agency to monitor contracts with agencies in that sector more closely.

The last factor included in the second stage of our framework is political pressure. Client advocacy groups and politicians frequently pressure government agencies to improve the quality and quantity of services being delivered within a particular policy area. In highly politicized environments where a contractor provides the service being scrutinized, a government agency may decide to increase their monitoring efforts in hopes of improving service delivery outcomes. Alternatively, political pressure from outside groups has the potential to decrease monitoring efforts. In some cases, contractors are very powerful politically and are closely aligned with client advocacy groups. Under these circumstances, client advocacy groups may pressure politicians to reduce monitoring efforts.[32]

\section{STAGE THREE: CONTRACTOR PERFORMANCE}

In the discussion of the first stage of our framework we analyzed several factors affecting the decision to contract out. Many of these factors directly translate into the goals that government agencies pursue. This section presents a theoretical framework for understanding contractor performance, the degree to which these goals are achieved. The conceptual tool that we offer may be useful for researchers who attempt to verify whether various economic or ideological arguments for contracting out are actually justified in practice. The first portion of this section reviews the current approaches found in the literature and proposes an alternative framework. The remainder of the section details a number of factors that are likely to impact contractor performance.

A large part of empirical literature on contractor performance focuses on a single outcome: cost-effectiveness. Some authors support the assumption that contracting out generally leads to noticeable cost savings.[8,25,49] Others argue that due to methodological limitations, the actual cost-savings from the private provision of services are not clear and may be overstated.[15,24,50,51] Almost uniformly, the latter group of researchers point out that the impact of contracting out on service quality is uncertain. According to Cooper,[52] efficiency considerations are commonly reduced to comparing the amount of input to the amount of output, rather than to the quality of output. However, the "bottom line is not simply about quantity but also quality.'"[52] Methodological obstacles in examining contractors' performance include the absence of relevant control variables in the analyses,[49,50] lack of pre-tests and preassessments, [53] samples suffering from selection biases, [51] inadequate outcomes measurement,[51] lack of consideration of tax consequences, [51] and other hidden costs.[15] In fairness to this issue, the methodological problems in assessing the impact of contracting out are not uncommon for most other public-sector restructuring exercises, such as marketization, agencification, and privatization.

Our framework separates contractor performance into three dimensions: structure, process, and outcomes. This approach is based on the framework for quality assessment originally proposed by Donabedian.[54] While the use of Donabedian's framework has been primarily limited to evaluating the quality of healthcare, the framework could also be applied to the perfor-mance of any public programs. In Donabedian's framework, structure refers to service delivery inputs. A government agency can evaluate contractor performance by monitoring the extent to which the contractor uses the inputs mentioned in the contract. Examples of inputs likely to be monitored include contractor personnel and facilities. With respect to process, contractors can be evaluated in terms of whether services are delivered in a way that is consistent with contract conditions and accepted professional norms. Another important dimension of 
quality relates to outcomes. In the literature applying Donabedian's framework, outcomes refer to the extent to which the "good events" rather than "bad events" occur. This framework has been adopted not only in healthcare literature but also in the field of procurement.[55] Applying this general definition to contracting out, "good events" in our framework refer to the extent to which a contractor achieves general and specific service delivery objectives. On the other hand, "bad events" occur when the contract results in negative consequences.

By viewing structure and process apart from outcomes, it is possible to separate aspects of quality that are closely related to provider compliance with contract requirements from those that depend on additional factors. Complying with structure and process requirements increases the likelihood of good outcomes but does not assure them.[56] When considering this framework as a tool for evaluating the quality aspects of contractor performance, the measure for the structure and process are mostly service-specific. Drawing on Kane,[57] outcomes can be separated into two large classes: "specific" and "global." The specific measures often relate to the concrete changes in client behavior and status. Some of the global measures of outcomes discussed below pertain to the overall "societal" impacts of the contract. In fact, most of them can be easily translated into more concrete and specific measures.

One example of the global outcome measures is cost-effectiveness, mentioned earlier in our discussion. Cost-effectiveness is one of the most common outcomes considered by the researchers and practitioners when evaluating contractor performance. One important caveat is that for a contract to be considered cost-effective it must be cost-effective for both the contractor and the government agency. Such assessments should not disregard the trans-action costs incurred by the government to examine contractor performance. While cost-effectiveness can be considered to be a global measure, it can also be translated into multiple specific measures of cost-effectiveness for each concrete component of the service delivery.

The "global" outcome measures of contractor performance should not be limited to only cost-effectiveness considerations. There are other outcome measures that are found in the literature and need closer consideration. Such measures include responsiveness to consumers,[49,52] equity and distributional concerns,[49,51,52] responsibility,[52] community economic development,[24] and client satisfaction.[1] We are not going to consider these measures in depth in this text. Our goal is simply to look for the concepts that fit with our understanding of the global outcome measures, and point out the necessity of their further explication and operationalization.

The current theoretical literature tends to compare program performance for services that are contracted out with services provided by the government. In contrast, our discussion of this stage focuses on the likely impact of various factors within the existing contracting context. In other words, our emphasis is on the different factors that are likely to improve contractor performance once the contracting arrangement has been made. However, this does not mean that our framework cannot be used to make comparisons across different service delivery methods. Such comparisons can be made by examining samples with both types of arrangements and including a dummy variable for "contracting" as a control variable.

Several factors are likely to affect contractor performance and are depicted in Figure 4. The third stage of our framework is a logical extension of the second stage, as the second stage's dependent variable, effective monitoring, becomes one of the factors explaining contractor performance in Stage 3. Based on agency theory, effective monitoring minimizes the possibility that the government agency will face moral hazard or adverse selection.[31] If information that allows the principal to monitor the agent's activities is available, the likelihood the agent will 
behave in the way that principals want increases because it will be more difficult for the agent to deceive the principal.[47,58,59] Following the agency theory, many theorists of contracting warn against over-reliance on market mechanisms and argue that the capacity to monitor service provision by collecting and evaluating perfor-mance data and providing appropriate feedback is critical.[1,6,33,55,60] Some empirical evidence suggests that contractors may often view government monitoring as micromanagement, a disruptive and dysfunctional intrusion into the process of implementation.[38,61] However, in many cases effective monitoring is viewed by contractors as an important tool that forces the providers to think in terms of results.[38]

While effective government monitoring can enhance contract outcomes, it is the contractors who are ultimately responsible for service delivery.

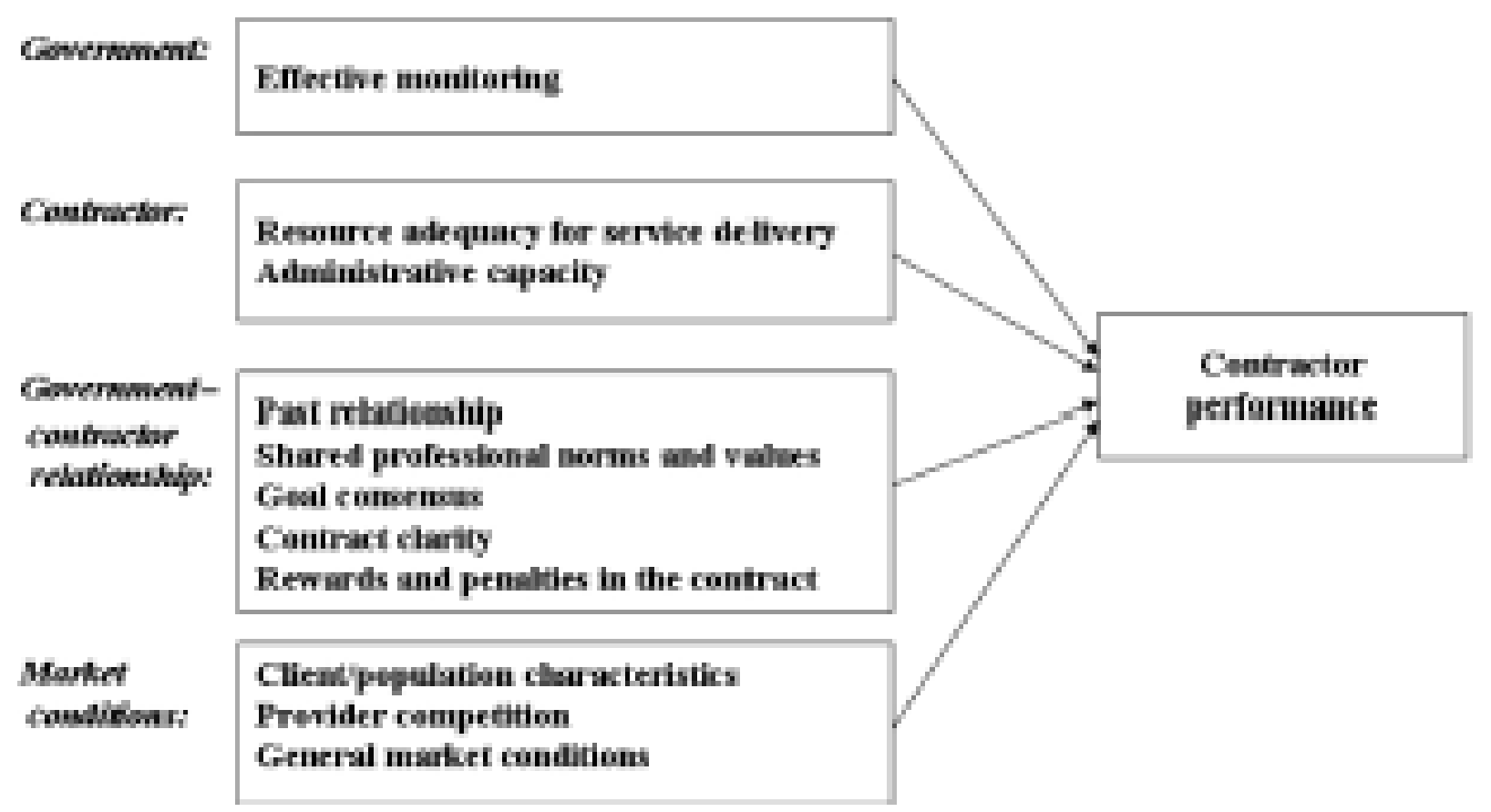

Figure 4. Stage 3: Contractor performance.

As a consequence, Stage 3 includes factors that are related to contractor capacity. As detailed in Stage 2, the existence of adequate resources for service delivery is likely to be critical for successful program implemen-tation. Empirical research suggests that well-funded systems operate better.[1] Cash-flow problems can hamper the ability of a contractor to purchase the personnel, facilities and technology needed to deliver adequate services.[34] Importantly, adequacy of resources should be assessed with respect to the volume of the output such as the number of clients. In other words, what may be considered an adequate funding for 50 units of output may not necessarily be adequate for 500 units of output.

In addition to having stable and sufficient resources, contractors must have adequate administrative capacity in order to ensure that resources are efficiently distributed. Contracting arrangements often entail more complex personnel and project management due to the new tasks performed by the organization. As a result, the complexity of administration in agencies receiving government contracts is likely to increase. One would expect that contractor performance would be better in agencies with sufficient adminis-trative capacity than in agencies that lack such capacity.[34] 
Another set of factors that affect contractor performance relates to the governmentcontractor relationship. As described in the preceding section, past relationships, as well as the existence of shared professional values, may compel some contractors to satisfy contract requirements more than the fear of adverse sanctions. Both of these variables are also theorized to directly affect contractor performance.

Kelman[42] argues that the existence of long-term relationships between government and contractors fosters transaction-specific investments. Through repeated interactions, contractors learn about the government's service delivery system and may offer helpful suggestions for how service delivery can be improved. These improvements, in turn, may positively impact contractor performance. Moreover, partnerships with long and productive histories are likely to foster informal ties and a sense of responsibility and obligation between organizations that will stimulate contractor performance. Such relationships may impact performance even in the absence of close monitoring. Supporting this argument, Milward and Provan's pioneering work on four mental health networks finds that stability was in fact more important than resources. Their analysis shows that one of the poorly-funded systems in fact performed better than one of the well-funded systems, which was going through a period of instability and readjustment. In the latter system, insta-bility was likely to result in ineffectiveness before improvement was seen. For the same reason, bidding out frequently may save some money, but it may be destructive to system stability and, by extension, performance.[1,62]

In addition, even in the absence of prolonged relationships, two organi-zations having similar professional values will be more likely to have the same understanding of various facets of service provision. Consequently, contractors in these types of contracting relationships will be more likely to perform according to the government agency's expectations.

The previous section has discussed how goal consensus can reduce communication problems and enhance the likelihood of agreement regarding monitoring tools. Similarly, goal consensus is expected to directly affect contractor performance. For example, due to the information asymmetry between the principals and agents, the government agency may prioritize global goals, such as equity and empowerment. On the other hand, the contractor may focus on more specific objectives stated in the contract such as changing behavior and improving clients' status, objectives that do not necessarily empower or redistribute resources. As a result, lack of goal consensus is likely to produce results that are not adequate for at least one side of the relationship.

Another factor included in both the second and third stages of our framework is contract clarity. In cases where a contract is clearly written, it will be easier for the contractor to understand the government agency's expectations regarding the process, structure, and outcomes. In the absence of a clearly written contract, one would expect a contractor to more likely to be guided by its own understanding of programmatic goals, which may not necessarily reflect those of the government agency. However, the lack of a clearly written contract does not inevitably result in negative conse-quences. Literature points out that the role of written contracts may be quite limited compared to the interorganizational embeddedness and social relations between organizations.[63] For example, psychological contracts are a legitimate way of regulating partnerships through unwritten and mainly unspoken assumptions and expectations as opposed to clearly written formal documents.[64,65] Such informal and sometimes quite vague contracts may be a result of the problem inherent in the principal-agent relationship: inability to anticipate all conditions and behavior of the agent. This factor, combined with the lack of goal clarity in many public services, may in fact discourage having much clarity in written contracts. 
In addition, the presence of rewards and penalties in the contract can impact contractor performance. The effectiveness of "incentivizing" contractor performance is confirmed empirically and substantiated by a variety of organizational theories, such as resource dependence theory, transaction costs economics theory, corporate social responsibility theory, and others.[66] Incorporating performance appraisal into the contract through appropriate rewards and penalties serves as an incentive mechanism positively affecting contractor performance by aligning the goals of the contractor and the government agency.[18] The idea of performance-based incentives has been attached to many public-sector reforms around the world.

The last broad category of factors likely to influence contractor perfor-mance is market conditions. The concept of market is approached quite broadly here. It incorporates the client characteristics, competition, and general market trends Client/population characteristics is the first environmental factor affecting contractor performance. Our understanding of client population characteristics is close to the concept of "case-mix" in the healthcare literature. Imagine two very similar contractors delivering the same service to two different populations. Naturally, the contractor that serves a more disadvan-taged and "difficult" group of clients would have a harder time achieving the same level of outcomes than its counterpart. The population that is financially and educationally more vulnerable is likely to require more attention, effort, and varied levels of services tied to their extraordinary needs.

In addition to enhancing the likelihood of effective monitoring, provider competition can directly impact contractor performance. In an industry with multiple competitors, one would expect a contractor to be more mindful of a government agency's ability to hire another contractor in case of an inadequate outcome. As a result, provider competition is likely to stimulate better contractor performance.

The final factor included in our framework is general market conditions. As previously discussed, an overall decline in revenues for a particular market sector may result in agencies in this sector trying to receive government reimbursement for activities that were not intended to be covered by government contracts. As a result, there will be fewer resources available to meet contract requirements, and this is expected to seriously jeopardize contractor performance.

\section{CONCLUSION}

Currently, public agencies are intensively experimenting with various alter-native forms of service delivery. Ingraham[67] argues that it has become typical for the government to apply private-sector strategies for public-sector solutions. Meanwhile, the literature calls for more attention to clear problem specification, examination of the causal linkages, and good assessment of the likelihood of success in order to enhance the effec-tiveness of various policy transfers from one unit of government to another and from the private to public sector.[67] Focusing on one of the most prevalent alternative service delivery mechanisms, this study found that very little research comprehensively analyzes the rationale for its adoption. Our article attempts to integrate the existing theoretical explanations of the contracting decision into a theoretical framework, distinguishing the role of institutional forces, political, or organizational factors in the decision to contract out.

In addition to examining the predictors of contracting decision, we focus on its outcomes. Commenting on the results of the privatization, Rainey and Steinbauer[68] note that the assessments of the privatization initiatives commonly find more modest results than the ones projected by the propo-nents of privatization. The evaluations of contracting-out practices share the same sense of disappointment and uncertainty. In order to cope with the new role of 
government agencies, research highlights the importance of building government capacity to better coordinate and evaluate program implementation.[69] In our framework we link an increasingly important aspect of government capacity, effective contract monitoring, with contractor perfor-mance. We detail the factors that contribute to the effective monitoring of public contracts and argue that their presence is as important as the role of competition and contractor capacity.

Lynn, Heinrich, and Hill[70] point out that governance research encom-passes three levels of government: institutional, managerial, and technical. The new governance approach provides an alternative to the prevailing focus on management in the public administration literature. Our framework attempts to bring together factors that influence contracting practices on all three levels mentioned by Lynn, Heinrich, and Hill. The framework is intended to allow researchers to think more broadly about the contracting questions and see the connections between the initiation of the restructuring process and the outcomes of contracting out.

The broad theoretical model presented in this article may offer a useful framework for guiding future research on contracting out. The next logical step in applying our framework is to propose specific hypotheses on inter-dependencies among different factors. For instance, in Stage 1, viewing the contracting decision as a multi-phase process may generate hypotheses on how different factors impact different phases of that process. In the agenda-setting phase, decision makers select, define and focus on particular problems.[71] Organizational politics and ideology often determine restructuring priorities, while budgetary constraints motivate managers to explore various forms of privatization. Therefore, monetary considerations and the political context of the contracting-out decision may have a stronger impact in this phase of the policymaking process than other factors. Once contracting out is placed on the agenda, the phase of policy formulation follows in which public officials explore various policy options and formulate alternative policies.[71,72] The organizational context may have especially strong impact in this phase of contracting decision. This happens because managers' perception of various capacities influences the way they explore policy options and formulate policy alternatives. After a contracting-out proposal is designed, a decision regarding whether the proposal is adopted is typically made. During this phase, it is critical that the proposal is supported by the majority of the stakeholders[7,72] and does not conflict with the current regulations. In situa-tions where there is political pressure to contract out and when the proposal is consistent with any institutional constraints, the likelihood that the proposal will be adopted increases. This is an example of just one of the many interesting sets of hypotheses that can be generated based on our model.

Additional possible areas for further research on this topic may include:

1. examining other interdependencies among various factors,

2. applying general concepts to specific policy areas and proposing other interesting hypotheses,

3. testing models that control for the range of factors identified in this study, and

4. further specifying our theories by examining the comparative impact of various factors, including specifying theories for specific policy areas.

We recognize that empirically testing this model is likely to pose major difficulties. Examples of the difficulties that may be posed include the opera-tionalization of the concepts, data collection, and potential endogeneity biases. Most of the phenomena discussed in this 
article, such as political pressure, political ideology, and various aspects of contract outcomes still need to be carefully specified and defined. Some constructs, such as well-designed monitoring tools, may be best operationalized by using both subjective, perception-based measures and objective measures based on specific theoreti-cally substantiated criteria. It may also be challenging to collect the necessary data needed to empirically test our framework. For example, collecting data on stakeholders' involvement in the contracting process and nonmonetary contract outcomes may prove to be daunting. One of the data sources produced and utilized by researchers to answer questions similar to the ones discussed in this paper is The Alternative Service Delivery in Local Government data, collected as a part of the International City Management Association surveys.[73] The richness of the context and multiple levels of data sources 3 should perhaps encourage the use of a combination of qualitative and quanti-tative methods in such research.

When specifying quantitative models, researchers should be cautious of the recursive relationships and complex interdependencies that are inherent to our theory. As a result, researchers may be confronted with the need to use more sophisticated statistical techniques to identify the magnitude of the association, such as the association between contractor performance and past government/contractor relationship. Furthermore, due to the complexity of the framework, the most feasible solution may be to focus on testing only limited parts of the larger framework. However, it is important that they acknowledge the limitations of such narrow approaches.

In addition to greater in-depth examination of the questions on which we focused in this article, future research could examine other important questions associated with contracting public services. We focused on just two aspects of the contracting-out process:

1. why government agencies decide to contract out services, and

2. why contractor performance varies.

In addition to these "why" questions, questions that ask "how" are also important. Specifically, further research is needed to describe the growth of contracting out and how it varies across different services within the public sector. Other areas of research include exploring how the role of managers in government agencies and the relationship between government agencies and private organizations change as contracting out becomes more widespread. Answering all of these questions will not only improve our understanding of the contracting-out process but also clarify the role of this new service delivery mechanism in the larger governance paradigm.

\section{REFERENCES}

1. Milward, H. B.; Provan, K. G. Governing the Hollow State. Journal of Public Administration Research and Theory 2000, 10, 359-379.

2. Kelman, S. J. Contracting. In The Tools of Government: A Guide to the New Governance; Salamon, L.M., Ed.; Oxford University Press: New York., 2002; 282-318.

3. Hirsch, W. Z. Factors Important in Local Governments' Privatization Decisions. Urban Affairs Review 1995b, 31, 226-243.

4. Donahue, J. D. The Privatization Decision: Public Ends, Private Means; Basic Books: New York, 1989. 
5. Hirsch, W. Z.; Osborne, E. Privatization of Government Services: Pressure-Group Resistance and Service Transparency. Journal of Labor Research 2000, 21, 315-326.

6. Kettl, D. F. Sharing Power: Public Governance and Private Markets; 7 The Brookings Institution: Washington, DC, 1993.

7. Savas, E. S. Privatization and Public-Private Partnerships; Chatham House Publishers: New York, 2000.

8. Seidenstat, P. Privatization: Trends, Interplay of Forces, and Lessons Learned. Policy Studies Journal 1996, 24, 464-477.

9. Seidenstat, P. Contracting Out Government Services; Praeger: Westport, CT, 1999.

10. Wilmot, C.G.; Deis, D.R.; Xu, R. Assessing Outsourcing Potential in a State DOT. Journal of Public Procurement 2004, 4(1), 22-42.

11. Greve, C. New Avenues for Contracting Out and Implications for a Theoretical Framework. Public Performance and Management Review 2001, 24, 270-284.

12. Clynch, E. J. Contracting and Government: Some Further Thoughts. Public Administration and Management 1999, 4, 325-331.

13. Ott, J. S.; Dicke, L. A. Important but Largely Unanswered Questions about Accountability in Contracted Public Human Services. International Journal of Organizational Theory and Behavior 2000, 3, 283-317.

14. DeHoog, R. H.; Salamon, L. M. Purchase-Of-Service contracting. In The Tools of Government: A Guide to the New Governance; Salamon, L.M., Ed.; Oxford University Press: New York, 2002; 319-339.

15. Smith, S. R.; Lipsky, M. Nonprofirts for Hire: The Welfare State in the Age of Contracting; Harvard University Press: Cambridge, MA, 1993.

16. DeHoog, R. H. Contracting out for Human Services; State University of New York Press: Albany, NY, 1984.

17. Morgan, D. R. The Pitfalls of Privatization: Contracting without Compe-tition. American Review of Public Administration 1992, 22, 251-269.

18. Lawther, W.C. Contracting for the 21st Century: A Partnership Model. In Abramson, M.A., Harris R.S. III, Eds. The Procurement Revolution; Rowman \& Littlefield: Lanham, MD, 2003; 167-213.

19. Avery, G. Outsourcing Public Health Laboratory Services: A Blueprint for Determining Whether to Privatize and How. Public Administration Review 2000, 60, 330-337.

20. Deis, D.R.; SchneiderH.; Wilmot, C.G.; Coats, C.H. A Simulation Approach to In-House Versus Contracted Out Const Comparisons. Journal of Public Procurement 2004, 4(1), 43-66. 21. Moe, T. M. The New Economics of Organization. Journal of American Political Science 1984, 28, 739-777.

22. Ang, S.; Straub, D. W. Production and Transaction Economies and IS Outsourcing: A Study of the U.S. Banking Industry. MIS Quarterly, 22, 535-562.

23. Globerman, S.; Vining, A. R. A Framework for Evaluating the Government ContractingOut Decision with an Application to Information Technology. Public Administration Review 1996, 56, 477-586.

24. Van Slyke, D. M. The Mythology of Privatization in Contracting for Social Services. Public Administration Review 2003, 63, 296-315.

25. Domberger, S.; Rimmer, S. Competitive Tendering and Contracting in the Public Sector: A Survey. International Journal of the Economics of Business 1994, 1, 439-453. 
26. Johnston, J. M.; Romzek, B. S. Contracting and Accountability in State Medicaid Reform: Rhetoric, Theories and Reality. Public Administration Review 1999, 59, 383-399.

27. Behn, R. D.; Kant, P. A. Strategies for Avoiding the Pitfalls of Perfor-mance Contracting. Public Productivity and Management Review 1999, 22, 470-489.

28. Guttman, D. Public Purpose and Private Service: The Twentieth Century Culture of Contracting Out and the Evolving Law of Diffused Sovereignty. Administrative Law Review 2000, 52, 859-926.

29. Rainey, H. G. Understanding and managing public organizations; Jossey-Bass Inc.: San Francisco, CA, 1997.

30. Peters, B. G. The Politics of Tool Choice. In The Tools of Government: A Guide to the New Governance; Salamon, L.M., Ed.; Oxford University Press: New York, 2002; 552-564. 31. Weissert, C. S. Reluctant Partners: The Role of Preferences, Incentives, and Monitoring in Program Compliance. Journal of Public Administration Research and Theory 2001, 11, 435453.

32. Romzek, B. S.; Johnston, J. M. Effective Contract Implementation and Management: A Preliminary Model. Journal of Public Administration Research and Theory 2002, 12, 423-453.

33. Brown, T. L.; Potoski, M. Contract-Management Capacity in Municipal and County Governments. Public Administration Review 2003, 63, 153-164.

34. Romzek, B. S.; Johnston, J. M. Reforming Medicaid through Contracting: The Nexus of Implementation and Organizational Culture. Journal of Public Administration Research and Theory 1999, 9, 107-139.

35. Kane, J. S.; Lawler, E. E., III Performance Appraisal Effectiveness: Its Assessment and Determinants. In Research in Organizational Behavior; JAI Press: Greenwich, CT, 1979; 425478.

36. Ingraham, P. W. Linking Leadership to Performance in Public Organiza-tions; (PUMA/HRM (8)/Final). OECD, 2001.

37. Meier, K. J. The Case for More Bureaucracy and Less Democracy. Public Administration Review 1997, 57, 193-199.

38. Bernstein, S. R. Managing Contracted Services in the Nonprofit Agency; Temple University Press: Philadelphia, 1991.

39. Jackson, S.E.; Dutton, J.E. Discerning Threats and Opportunities. Admin-istrative Science Quarterly 1988, 33, 370-387.

40. Bennett, C.; Ferlie, E. Contracting in Theory and in Practice: Some Evidence from the NHS. Public Administration 1996, 74, 49-66.

41. Smith, S. R. Transforming Public Services: Contracting for Social and Health Services in the U.S. Public Administration 1996, 74, 113-127.

42. Kelman, S. Procurement and Public Management: The Fear of Discretion and the Quality of Government Performance; American Enterprise Institute: Washington, DC, 1990.

43. Wang, S.; Bunn, M.D.; Government/Business Relationships: Insights into contract Implementation. Journal of Public Procurement 2004, 4(1), 84-115.

44. Matland, R. E. Synthesizing the Implementation Literature: The Ambiguity-Conflict Model of Policy Implementation. Journal of Public Administration Research and Theory 1995, 5, $145-174$.

45. Meyers, M. K.; Riccucci, N. M.; Lurie, I. Achieving Goal Congruence in Complex Environments: The Case of Welfare Reform. Journal of Public Administration Research and Theory 2001, 11, 165-201. 
46. Van Meter, D. S.; Van Horn, C. E. Policy Implementation Process. Administration and Society 1975, 6, 445-488.

47. Eisenhardt, K.M. Agency Theory: An Assessment and Review. Academy of Management Review 1989, 14, 57-74.

48. Moe, T. M. Control and Feedback in Economic Regulation. American Political Science Review 1985, 79, 1094-1116.

49. Savas, E. S. Privatization: The Key to Better Government; Chatham House Publishers, Inc.: Chatham, NJ, 1987.

50. Boyne, G. A. Bureaucratic Theory Meets Reality: Public Choice and Service Contracting in U.S. Local Government. Public Administration Review 1998, 58, 474-484.

51. Hirsch, W. Z. Contracting Out by Urban Governments: A review. Urban Affairs Review 1995a, 30, 458-472.

52. Cooper, P. J. Governing by Contract; Congressional Quarterly Press: Washington, DC, 2003.

53. Blasi, G. J. Government Contracting and Performance Measurement in Human Services. International Journal of Public Administration 2002, 25, 519-538.

54. Donabedian, A. Evaluating the Quality of Medical Care. Milbank Memorial Fund Quarterly 1966, 44, 166-206.

55. Martin, L.L. Making Performance-Based Contracting Perform: What the Federal Government Can Learn from State and Local Governments. In Abramson, M.A., Harris, R.S. III, Eds. The Procurement Revolution Rowman \& Littlefield: Lanham, MD, 2003; 87-125.

56. Kane, R. L. Assuring Quality in Nursing Home Care. Journal of the American Geriatrics Society 1998, 46, 232-237.

57. Kane, R. L. Improving the Quality of Care. Journal of American Medical Association 1995, 273, 1376-1380.

58. Arrow, K.J. The Economics of the Agency. In Principals and Agents: The Structure of Business; Pratt, J.W., Zeckhauser, R.J., Eds.; Harvard Business School Press: Boston, 1984; 135.

59. Coats, J. Applications of Principal-Agent Models to Government Contracting and Accountability Decision Making. International Journal of Public Administration 2002, 25, 441461.

60. Klingner, D. E.; Nalbandian, J.; Romzek, B. S. Politics, Administration, and Markets: Conflicting Expectations and Accountability. American Review of Public Administration 2001, 32, 117-144.

61. Mayer, K. Policy Disputes as a Source of Administrative Controls: Congressional Micromanagement of the Department of Defense. Public Administration Review 1993, 53, 293301.

62. Provan, K. G.; Milward, H. B. A Preliminary Theory of Interorganiza-tional Network Effectiveness: A Comparative Study of Four Community Mental Health Systems. Administrative Science Quarterly 1995, 40, 1-33.

63. Granovetter, M. Economic Action and Social Structure: The Problem of Embeddedness. American Journal of Sociology 1985, 91, 481-510.

64. Ring, P.S.; Van de Ven, A.H. Developmental Processes of Cooper-ative Interorganizational Relationships. Academy of Management Review 1994, 19, 90-118. 
65. Rousseau, D.M. Psychological Contracts in Organizations: Under-standing Written and Unwritten Agreements; Sage Publications: 1005 Thousand Oaks, CA, 1995.

66. L'Heureux , M.R.A.; Block, J.A. Corporate Environmental Responsi-

bility: An Examination of Incentivization. National Contract Management Journal 1996, 27, 5970 .

67. Ingraham, P. Of Pigs in Pokes and Policy Diffusion: Another Look at 1010 Pay-forPerformance. Public Administration Review 1993, 53, 348-356.

68. Rainey, H.; Steinbauer, P. Galloping Elephants: Developing Elements

of Theory of Effective Government Organizations. Journal of Public Administration Research and Theory 1999, 9, 1-32.

69. Dilulio, J.; Garvey, G.; Kettl, D. Improving Government Performance. 1015 An Owner's Manual; The Brookings Institution: Washington, DC, 1993.

70. Lynn, L. E., Jr.; Heinrich, C. J.; Hill, C. J. Improving Governance: A New logic for Empirical Research; Georgetown University Press: Washington, DC, 2000.

71. Kingdon, J. W. Agendas, Alternatives, and Public Choices; Little, Brown 1020 and Company: Boston, 1984.

72. Dunn, W. N. Public Policy Analysis: An Introduction, 2nd Ed.; Prentice Hall: Englewood Cliffs, NJ, 1994.

73. Hefetz, A.; Warner, M.E. Privatization and its Reverse: Explaining the Dynamics of the Government Contracting Process. Journal of Public 1025 Administration Research and Theory, Formcoming 2003. 